\title{
The benzodiazepines: recent trends ${ }^{1}$
}

The benzodiazepines have now been available to the clinician for over 20 years, since the introduction of chlordiazepoxide (Librium) in 1960. The broad and unique spectrum of activity of these compounds as anxiolytics, hypnotics/sedatives, anticonvulsants and muscle relaxants, together with their low toxicity and an essential absence from peripheral side-effects, has resulted in compounds of this class becoming the most frequently prescribed of all psychotropic drugs. Although it is difficult to obtain an accurate estimate of their usage in England, in Canada 1 in 10 of the population receives a prescription for these drugs each year, while over $30 \%$ of hospitalized patients is given one or other of these agents (Ban et al. 1981).

\section{USE OR OVER-USE}

The indications are that the benzodiazepines are suffering a significant though small decline in their popularity, but their continued widespread use has resulted in some disquiet concerning their over-use. A number of cases of dependence on these compounds has been reported, though with respect to their widespread usage the percentage of such difficulties is extremely small and rarely becomes apparent without long-term administration of the compounds. However, with regard to their anxiolytic activity recent evidence from Davis et al. (1981) in Oxford would contra-indicate such prescription habits. It is well known that animals subjected to certain stressful situations are able to adapt to their new environment over a period of time. The Oxford group has found that the benzodiazepines are able to inhibit this adaptation response, and the results of experiments so far indicate that such inhibition can occur in situations normally experienced by man (J. A. Gray, personal communication). This would imply that, while short-term usage of the benzodiazepines to overcome some acute anxiety problem is acceptable, continued ingestion of the compounds would reduce the ability to cope with stressful situations.

\section{THE PROLIFERATION OF COMPOUNDS}

There is little evidence that the pharmacological profile of any single compound among the many now available to the clinician is significantly different from any other: i.e. all produce sedation/anxiolysis in approximately the same proportions. It is, however, possible to use an appropriate drug to accentuate a particular effect by relying on the differing pharmacokinetic profiles of the compounds; for example, the choice of one of short biological half-life for night time sedation and a compound with a longer biological half-life if the drug effects are to be protracted, as in the treatment of anxiety. The fact that all of the compounds currently available display the varying aspects of their pharmacological profile to a similar extent has provided a considerable impetus for research into the mechanisms of action of these drugs, in the hope that compounds might be found with a more restricted spectrum of activity.

\section{THE BENZIODIAZEPINE RECEPTOR: EARLY DAYS}

The observations made independently in 1977 by Squires \& Braestrup in Copenhagen and Möhler \& Okada in Basle, that the mammalian brain possesses specific receptors for the benzodiazepines,

\footnotetext{
I Address for correspondence: Dr 1. L. Martin, MRC Neurochemical Pharmacology Unit, Medical Research Council Centre, Medical School, Hills Road, Cambridge CB2 2QH.
} 
produced a remarkable explosion of research interest in these compounds. These initial experiments showed, with the use of radioactively labelled diazepam, that binding sites existed on cell membranes in the mammalian CNS which recognized the benzodiazepines specifically and with high affinity. Many further experiments have since been carried out which suggest that these 'binding-sites' are part of the receptor complex through which the benzodiazepines exert their effects.

Initially, it was thought that the benzodiazepine receptors consisted of a single homogeneous population, and the inference was therefore that all of the pharmacologial actions of these drugs were mediated via this single receptor. However, work by Squires et al. (1979) indicated that the triazolopyridazine CL 218872 (see Fig. 1) was able to displace diazepam from its binding sites in<smiles>CN1C(=O)CN=C(c2ccccc2)c2cc(Cl)ccc21</smiles><smiles>CCOC(=O)c1cc2c(cn1)[nH]c1ccccc12</smiles>

Ethyl $\beta$-carboline-3-carboxylate

Diazepam<smiles>Cc1nnc2ccc(-c3cccc(C(F)(F)F)c3)nn12</smiles>

CL218872<smiles>CCOC(=O)c1ncn2c1CN(C)C(=O)c1cc(F)ccc1-2</smiles>

RO 15-1788<smiles>O=c1c2c[nH]c3ccccc3c-2nn1-c1ccccc1</smiles>

CGS 8216

Fig. 1.

a manner which indicated that two binding sites existed: sites which could be differentiated by this compound but not by diazepam. The further claim (not since confirmed) that this compound produced anxiolytic and anti-convulsant effects but little sedation aroused intense interest, the hypothesis being that one of the receptor subtypes was responsible for the sedative effects of the benzodiazepines, while the other mediated the anxiolytic and anti-convulsant actions. Further support was added to the multiple site hypothesis by studies on the thermal inactivation of benzodiazepine receptors, the stability of which could not be adequately explained by the assumption that only a single homogeneous population of receptors existed (Squires et al. 1979). 


\section{THE BENZODIAZEPINE RECEPTOR: ONE OR TWO?}

In searching for the endogenous ligand for the benzodiazepine receptor Braestrup et al. (1980) obtained a compound ethyl $\beta$-carboline-3-carboxylate $(\beta$-CCE) from human urine (see Fig. 1). Although it is now clear that this compound was an experimental artefact, $\beta$-CCE nevertheless has an extremely high affinity for the benzodiazepine receptor and has proved to be an extremely valuable experimental tool.

This compound was found to be potent in displacing radiolabelled diazepam from CNS membranes, but its potency varied depending on which brain region had been used to prepare the membranes. It was suggested that the explanation of this phenomenon was that two subtypes of benzodiazepine existed, a $\mathrm{Bz}$ type with a high affinity for $\beta$-CCE (1 nM) and a $\mathrm{Bz}_{2}$ type with a lower affinity (about $12 \mathrm{nM}$ ), though both subtypes appeared to show the same affinity for the benzodiazepines(Nielsen \& Braestrup, 1980). The numbers of these two subtypes varied independently in different brain regions, thus explaining the variation in potency for the displacement of the diazepam. Thus further support was obtained for the multiple receptor hypothesis. Subsequent behavioural work, however, revealed that $\beta$-CCE was a proconvulsant: i.e. the compound appeared to have actions diametrically opposed to those of the benzodiazepines (Oakley \& Jones, 1980; Tenen \& Hirsch, 1980; Cowan et al. 1981). Further derivatives were made and subsequent work with these compounds has shown the methyl ester to be a convulsant, while the $n$-propyl ester exhibits no overt actions alone but, like the benzodiazepines, is able to block the convulsions produced by the methyl ester (Jones \& Oakley, 1981).

While the $\beta$-carboline-3-carboxylates have markedly different actions with regard to anticonvulsant activity, their complete behavioural profile has not yet been fully investigated, due to the extremely short biological half-life of these compounds. It is clear, however, that $\beta$-CCE is able to suppress the increase in drinking produced by benzodiazepines under conditions thought to be predictive of anxiolytic acitivity (Brown \& Johnson, 1982) and to reverse the sedative effects of flurazepam (Cowan et al. 1981). However, all three of these esters are able to differentiate between the two proposed subtypes of benzodiazepine receptor in binding experiments with the same degree of preference, making the significance of these two receptor classes unclear.

It is, however, possible to distinguish the propyl ester (anti-convulsant) from the methyl ester (convulsant) by the fact that the affinity of the latter compound is significantly decreased by the presence of GABA and sodium chloride, while under identical conditions the affinity of the propyl ester is increased, in a manner similar to that displayed by the benzodiazepines. (Doble et al. $1982 \mathrm{~b}$ ). It is therefore possible to identify 'benzodiazepine-like' activity in the test tube by the fact that the affinity of such compounds for the receptor is increased in the presence of GABA and sodium chloride, while the affinity of compounds with the opposite behavioural actions is decreased. The effects of GABA suggest some interaction of benzodiazepines with this important inhibitory neurotransmitter in the brain. It is now widely believed that the activation of benzodiazepine receptors serves in some way to enhance GABA actions in brain.

While there is now considerable support for the hypothesis of multiple subtypes of the benzodiazepine receptor, other biochemical evidence suggests that the observations may be explained by different states, or conformations of the same receptor (Doble et al. 1982a). The significance of the existence of multiple subtypes of the receptor, in any case, remains unclear, although it continues to provide a considerable impetus to the research effort.

\section{BENZODIAZEPINE ANTAGONISTS}

Changes in the basic structure of the benzodiazepine molecule by the group at Hoffman la Roche have led to the development of antagonists to the actions of these compounds (Hunkeler et al. 1981). Ro 15-1788 (see Fig. 1) is one such example, having a high affinity for the benzodiazepine receptor. It is assumed that its remarkable ability to reverse specifically the actions of the 
benzodiazepines is due to its interaction at the receptor itself. However, the compound is also able to reverse effectively the actions of $\beta$-CCE, and this antagonism of two diametrically opposed actions has led to considerable speculation as to the nature of the interaction of these compounds with the benzodiazepine receptor (Nutt et al. 1982). While Ro 15-1788 is structurally related to the benzodiazepines, the compound CGS 8216 (see Fig. 1), from Ciba-Geigy, shows little such resemblance, though it exhibits a very high affinity for the receptor. Little further information is available about this compound so far, except that it is reported to antagonize the actions of the benzodiazepines by a direct interaction at the benzodiazepine receptor itself (Czernik et al. 1981).

\section{ENDOGENOUS LIGANDS FOR THE BENZODIAZEPINE RECEPTOR}

As the discovery of opiate receptor sites in the brain led, in turn, to the discovery of endogenous opioids (the enkephalins), so it was hoped that it might be possible to identify endogenous benzodiazepine-like compounds in the brain. This area of research, however, has proved to be a graveyard of dashed hopes (Martin, 1980), and arguments have been put forward concerning the necessity to envisage such a compound (see Möhler, 1981). The most recent reports concern a polypeptide found in the small intestine and bile duct which is able to displace competitively the benzodiazepines from their binding sites (Woolf \& Nixon, 1981). This compound, named nepenthin, has now been purified to apparent homogeneity and appears to have a molecular weight of $\sim 16000$, though the stability of its displacing activity after treatment with proteases suggests that a lower molecular weight fragment retains activity. Little is yet known about the compound, though anti-bodies prepared to the purified material have been used in double antibody labelling experiments on rat brain slices, the result of which suggest that an immunologically similar material is present in some cells of deep cortical regions of the forebrain.

\section{SUMMARY AND CONCLUSIONS}

The discovery of non-benzodiazepinoid compounds which are able to displace effectively the benzodiazepines from their receptors, together with the apparent existence of multiple types of this receptor, have resulted in new hopes that the different behavioural actions of these drugs can be effectively separated. Indeed, chemical modifications of the molecule have resulted in the preparation of effective antagonists and to compounds with a greater anxiolytic/sedative ratio than those currently available to the clinician. However, although we have a great deal of information concerning the neurochemical actions of these compounds, a detailed understanding of the structure-activity relationships in this series can only be attempted with similarly detailed clinical/ behavioural evidence concerning the profile of action of the individual compounds. Such a task is, of course, a daunting one but, unless we are to continue to rely on serendipity to provide us with compounds which exhibit more restricted profiles of action, this information must be obtained. Therefore it is perhaps in this field of endeavour where greater efforts and support must be sought in the future.

I. L. MARTIN

\section{REFERENCES}

Ban. T. A., Brown, W. T., Da Silva, T., Gagnon, M. A., Lamont, H. E., Leeman, H. E., Lowy, F. W., Ruedy, J. \& Sellers, E. M. (1981). Therapeutic monograph on anxiolytic-sedative drugs. Canadian Pharmaceutical Journal 114, 301-308.

Braestrup, C., Nielsen, M. \& Olsen, C. E. (1980). Urinary and brain $\beta$-carboline-3-carboxylates as potent inhibitors of brain benzodiazepine receptors. Proceedings of the National Academy of Sciences (USA) 77, 2288-2292.

Brown, C. L. \& Johnson, A. M. (1982). Ethyl $\beta$-carboline-3carboxylate reverses the effects of benzodiazepines in a test for detecting anxiolytic activity. British Journal of Pharmacology 75 , 43P.

Cowan, P. J., Green, A. R., Nutt, D. J. \& Martin, I. L. (1981). Ethyl $\beta$-carboline carboxylate lowers seizure threshold and antagonises flurazepam induced sedation in rats. Nature 290, 54-55.

Czernik, A. J., Petrack, B., Tsai, C., Granat, R. F., Rinehart, R. K., Kalinsky, H. J., Lovell, R. A. \& Cash, W. D. (1981). High affinity occupancy of benzodiazepine receptors by the novel antagonist CGS-8216. Pharmacologist 23, 160.

Davis, N. M., Brookes, S., Gray, J. A. \& Rawlins, J. N. P. (1981). 
Chlorodiazepoxide and resistance to punishment. Quarterly Journal of Experimental Psychology 33B, 227-239.

Doble, A., Iversen, L. L. \& Martin, I. L. (1982a). The benzodiazepine binding site: one receptor or two. British Journal of Pharmacology $75,42 \mathrm{P}$

Doble. A., Martin. I. L. \& Richards, D. A. (1982b). GABA modulation predicts biological activity of ligands for the benzodiazepine receptor. British Journal of Pharmacology 76, 238P.

Hunkeler, W., Möhler, H., Pieri, L., Polc, P., Bonetti, E. P., Cumin, R., Schaffner, R. \& Haefely, W. (1981). Selective antagonists of benzodiazepines. Nature 290. 514-516.

Jones, B. J. \& Oakley, N. R. (1981). The convulsant properties of methyl $\beta$-carboline-3-carboxylate in the mouse. British Journal of Pharmacology 74, 884P.

Martin, I. L. (1980). Endogenous ligands for benzodiazepine receptors. Trends in Neurosciences 3, 299-301.

Möhler, H. (1981). Benzodiazepine receptors: are there endogenous ligands in the brain? Trends in Pharmacological Sciences 1, 116-119.

Möhler, H. \& Okada, $T$. (1977). Benzodiazepine receptor: demonstration in the central nervous system. Science 198, 849-851.
Nielsen, M. \& Braestrup, C. (1980). Ethyl $\beta$-carboline-3-carboxylate shows differential benzodiazepine receptor interaction. Nature $\mathbf{2 8 6}$, 606-607.

Nutt, D. J., Cowan, P. J. \& Little, H. J. (1982). Unusual interactions of benzodiazepine receptor antagonists. Nature 295, 436438.

Oakley, N. R. \& Jones, B. J. (1980). The proconvulsant and diazepam reversing effects of ethyl $\beta$-carboline-3-carboxylate. European Journal of Pharmacology 68, 381-382.

Squires, R. F. \& Braestrup, C. (1977). Benzodiazepine receptors in rat brain. Nature 266, 732 734.

Squires, R. F., Benson, D. I., Braestrup, C., Coupet, J., Klepner, C. A., Myers, V. \& Beer, B. (1979). Some properties of brain specific benzodiazepine receptors: new evidence for multiple receptors. Pharmacology, Biochemistry and Behaviour 10, 825830 . Tenen, S. S. \& Hirsch, J. D. (1980). Antagonism of diazepam activity by $\beta$-carboline-3-carboxylic acid ethyl ester. Nature 288, 609-610.

Woolf, J. H. \& Nixon, J.C. (1981). Endogenous effector of the benzodiazepine binding site: purification and characterisation. Biochemistry 20, 4263-4269. 